BMJ Open Sport \& Exercise Medicine

\title{
Optimising secondary prevention in the acute period following a TIA of ischaemic origin
}

Neil Heron ${ }^{1,2,3}$

To cite: Heron N. Optimising secondary prevention in the acute period following a TIA of ischaemic origin. BMJ Open Sport Exerc Med 2016;1:e000161.

doi:10.1136/bmjsem-2016000161

- Prepublication history and additional material is available. To view please visit the journal (http://dx.doi.org/ 10.1136/bmjsem-2016000161)

Received 15 July 2016 Revised 18 October 2016 Accepted 27 November 2016

\section{CrossMark}

\section{${ }^{1}$ Department of General Practice and Primary Care, Queen's University, Belfast, UK \\ ${ }^{2}$ Centre for Public Health Research, Queen's University, Belfast, UK ${ }^{3}$ Centre of Excellence for Public Health Research, Queen's University, Belfast, UK}

Correspondence to Dr Neil Heron; neilheron@ yahoo.co.uk

\section{ABSTRACT}

Background: Transient ischaemic attacks (TIAs) are highly prevalent conditions, with at least 46000 people per year in the UK having a TIA for the first time. TIAs are a warning that the patient is at risk of further vascular events and the 90-day risk of vascular events following a TIA, excluding events within the first week after diagnosis when the risk is highest, can be as high as $18 \%$. Immediate assessment of patients with TIA, either at accident and emergency, general practice and/ or TIA clinics, is therefore required to address secondary prevention and prevent further vascular events.

Discussion: This article addresses the need for optimising secondary prevention in the acute period following a TIA of ischaemic origin to reduce the risk of further vascular events as per recent Cochrane review advice and presents a novel project, Stroke Prevention Rehabilitation Intervention Trial of Exercise (SPRITE), to do this.

Summary: One novel way to tackle vascular risk factors and promote secondary prevention in patients with TIA could be to adapt a cardiac rehabilitation programme for these patients. SPRITE, a feasibility and pilot study (ClinicalTrials.gov Identifier: NCT02712385) funded by the National Institute for Health Research, is attempting to adapt a home-based cardiac rehabilitation programme, 'The Healthy Brain Rehabilitation Manual', for use in the acute period following a TIA. The use of cardiac rehabilitation programmes post-TIA requires further research, particularly within the primary care setting.

\section{BACKGROUND}

\section{Definition of transient ischaemic attack}

Transient ischaemic attack (TIA) is defined as 'a transient episode of neurological dysfunction caused by focal brain, spinal cord or retinal ischaemia, without acute infarction' ${ }^{\text {, }}$ and is diagnosed by the patients' history, a neurological examination and/or neuroimaging (typically a CT head scan). Typical symptoms of TIA include the rapid onset of speech disturbance, unilateral weakness or sensory loss, monocular blindness, visual field defect or ataxia.

\section{What this study adds?}

Following a transient ischaemic attack (TIA), people are at risk of further cardiovascular events and this is a key time to initiate secondary cardiovascular prevention.

- Previous studies have focused on pharmacological secondary prevention following a TIA.

- However, there is a clear need to initiate nonpharmacological secondary cardiovascular measures, including physical activity promotion, following a TIA.

- One way to promote both pharmacological and non-pharmacological secondary cardiovascular prevention following a TIA is to adapt a homebased cardiac rehabilitation programme, 'The Healthy Brain Rehabilitation Manual', for this population following the Medical Research Council guidelines for developing complex health service interventions, which will be done within the Stroke Prevention Rehabilitation Intervention Trial of Exercise study.

Aetiology of TIAs: TOAST classification system The underlying aetiology of each TIA event can be classified as per the TOAST classification system. $^{2}$ The TOAST classification denotes the underlying cause of the TIA event and this paper focuses on secondary prevention following a TIA due to atherosclerosis or small vessel occlusion, two TOAST subtypes.

\section{TIA risk factors}

TIAs are most commonly caused by the embolic or thrombotic consequences of atherothrombotic disease, ${ }^{3}$ which is similar to the underlying pathological mechanism for cardiovascular disease. ${ }^{4-6}$ In addition to sharing a similar underlying pathological mechanism, cerebrovascular and cardiovascular disease share common underlying risk factors. ${ }^{5} 7$

The modifiable risk factors for all vascular diseases include smoking, excessive alcohol intake, physical inactivity, dietary factors, 
hypertension, dyslipidaemia, diabetes and obesity ${ }^{8}$ as well as low $\mathrm{VO}_{2 \max }$.

Thus, there are several lifestyle modifications that might contribute to a substantial reduction in the risk of vascular events post-TIA and there is evidence that the earlier these interventions can be introduced, the better the outcome. ${ }^{10} 11$

\section{Pharmacological secondary prevention of stroke}

National UK guidelines for the pharmacological treatment of TIA/stroke have been established by the National Institute for Health and Care Excellence (NICE) $^{12}$ and are supplemented by guidelines on tackling individual risk factors. Following the acute diagnosis of TIA, a prophylactic daily dose of $75 \mathrm{mg}$ of aspirin should be initiated and other agents, for example, dipyridamole and clopidogrel, may be added. These agents reduce blood clotting and therefore reduce the chances of a future clot forming within the circulation. Statins should be initiated to lower cholesterol levels ${ }^{13}$ and appropriate antihypertensive medications are used for blood pressure control ${ }^{14}$ as per national management guidelines. However, evidence is growing regarding the contribution of change in modifiable risk factors to reductions in deaths ${ }^{15}$ and there is a need to consider how to promote non-pharmacological measures within secondary prevention. ${ }^{16}$

\section{Non-pharmacological/ lifestyle risk factors \\ Physical activity}

Physical activity promotion and participation must be one of the key goals for modern-day health systems. Indeed, the WHO in $2010^{17}$ identified physical inactivity as the fourth leading risk factor for global mortality and this equates to $6 \%$ of global deaths. Following a TIA, patients should be encouraged to achieve at least the minimum recommended levels of physical activity as established by the chief medical officers and the departments of health. ${ }^{18}$

\section{Cardiorespiratory fitness}

Related to physical activity is cardiorespiratory fitness, which can be measured by $\mathrm{VO}_{2 \max }$, and is inversely correlated with mortality, ${ }^{19-22}$ the progression of carotid atherosclerosis ${ }^{23}$ and the risk of stroke. ${ }^{24}$ Myers et $a l^{25}$ found that in male subjects with and without cardiovascular disease, peak exercise capacity after adjustment for age was the strongest predictor of the risk of death and each one metabolic equivalent increase in exercise capacity conferred a $12 \%$ improvement in survival.

Exercise, a form of physical activity, can increase $\mathrm{VO}_{2 \max }$ in sedentary persons ${ }^{26}$ and in subacute stroke survivors. $^{27}$

\section{Smoking}

Smoking is a well-recognised vascular risk factor. The landmark prospective observational study by Doll et $a l^{28}$ found that British male doctors born between 1900 and 1930 who continued to smoke had a life expectancy 10 years less than that of lifelong nonsmokers. Smoking as a vascular risk factor has been continually supported by other studies, ${ }^{15} 29 \quad 30$ and patients with TIA should be advised about smoking cessation. $^{31}$

\section{Diet}

With regards to diet, a recent meta-analysis has shown that dietary fibre is inversely correlated with the risk of stroke, ${ }^{32}$ with fish oils also being protective. ${ }^{33}$ Indeed the 'Mediterranean diet' has shown favourable effects on cardiovascular risk factors. ${ }^{34}$ Moreover, hypercholesterolaemia, of which dietary intake may be a source, is a modifiable risk factor for cardiovascular and cerebrovascular diseases. ${ }^{35}$ Cholesterol levels were found to be positively associated with the risk of non-haemorrhagic stroke, ${ }^{36}$ and dyslipidaemia was also a significant risk factor for ischaemic stroke in the INTERSTROKE study. ${ }^{37}$ Patients with TIA should, therefore, be advised accordingly about their dietary habits.

\section{Stress}

Psychological distress is a well-known risk factor for TIAs. In the observational study by Everson-Rose et al, ${ }^{38} 6749$ adults free of vascular disease at baseline in the USA, aged 45-84 years old, were followed up for a median of 8.5 years as part of the Multi-Ethnic Study of Atherosclerosis. The authors found that higher levels of stress and depressive symptoms were associated with increased TIA risk, independent of other known vascular risk factors. Moreover, the diagnosis of TIA often leaves survivors with stress, anxiety and depressive symptoms. Indeed, a recent systematic review $^{39}$ has highlighted the prevalence of these often forgotten symptoms following a TIA and/or stroke diagnosis. Patients should therefore be educated about the signs and symptoms to be aware of and signposted appropriately for further management, with the general practitioner often as their first contact.

\section{Alcohol}

Alcohol excess is a well-known modifiable vascular risk factor, including for TIAs. Gill et $a l^{40}$ report the ' $\mathrm{J}$ shaped' association between alcohol and risk of stroke in a case-control study of approximately 1200 patients, that is, low alcohol consumption may have a protective effect for cerebrovascular events, whereas heavy consumption predisposes to TIAs. Safe alcohol consumption levels should therefore be promoted to patients with TIA to reduce the risk of future vascular events. ${ }^{41}$ 


\section{DISCUSSION}

\section{The 'evidence gap' from research to practice}

Despite the knowledge surrounding vascular risk factors and the recognition that TIAs are often the precursors of disabling strokes, more needs to be done in reducing stroke as the leading cause of adult disability. ${ }^{42}$ Indeed the WHO, as part of their 2013 Global Action Plan For the Prevention and Control of Non-Communicable Diseases, is trying to target a $25 \%$ relative risk reduction in overall mortality from cardiovascular diseases, including TIAs. ${ }^{43}$

One novel way to tackle vascular risk factors and promote secondary prevention in patients with TIA could be to adapt a cardiac rehabilitation programme for these patients. Indeed cardiovascular and cerebrovascular diseases share common underlying pathological mechanisms and risk factors. Moreover, cardiac rehabilitation after a myocardial infarction results in a statistically significant reduction in reinfarction (OR 0.53), cardiac mortality (OR 0.64) and allcause mortality (OR 0.74$),{ }^{44}$ and these findings concur with those of a recent Cochrane review. ${ }^{45}$ Although Heran et $a l^{45}$ report that the studies included in the review mainly comprise middle-aged men, who are generally at low cardiovascular risk and this should be considered when developing future studies in this area. A Cochrane review ${ }^{46}$ also demonstrated that hospitaland home-based cardiac rehabilitation programmes result in similar health gains, with home-based programmes improving adherence to the programme ${ }^{47}$ and promoting longer-term sustainability of health benefits. $^{48}$

The Stroke Prevention Rehabilitation Intervention Trial of Exercise (SPRITE) is a feasibility and pilot study (ClinicalTrials.gov Identifier: NCT02712385) funded by National Institute for Health Research (NIHR), which is attempting to adapt a home-based cardiac rehabilitation programme for use in the acute period following a TIA. The WHO has defined cardiac rehabilitation as the, 'sum of activity and interventions required to ensure the best possible physical, mental and social conditions so that patients with chronic or post-acute cardiovascular disease may, by their own efforts, preserve or resume their proper place in society and lead an active life'. ${ }^{49}$

NICE have recommended that the components of cardiac rehabilitation should include exercise, health education and stress management, ${ }^{50}$ helping to tackle the known vascular risk factors as previously documented. Health education would include addressing the known modifiable vascular risk factors as well as advice regarding work, mental health and sexual activity. ${ }^{50}$ These components will all be addressed within our adapted home-based cardiac rehabilitation programme, 'The Healthy Brain Rehabilitation Manual'. Such research has immediate clinical significance and the potential to change guidelines for the management of TIAs, as well as the potential to reduce morbidity and mortality resulting from TIAs, with clear benefit to patients.

\section{SUMMARY}

One novel way to tackle vascular risk factors and promote secondary prevention in patients with TIA could be to adapt a cardiac rehabilitation programme for these patients. SPRITE, a feasibility and pilot study (ClinicalTrials.gov Identifier: NCT02712385), is attempting to adapt a home-based cardiac rehabilitation programme, 'The Healthy Brain Rehabilitation Manual', for use in the acute period following a TIA. The use of cardiac rehabilitation programmes post-TIA requires further research, particularly within the primary care setting.

Acknowledgements I acknowledge my study supervisors (Professor Frank Kee, Professor Michael Donnelly, Professor Jonathan Mant and Professor Margaret Cupples) who were helping me to develop the SPRITE study.

Contributors NH conceived the study and drafted and revised the manuscript. Funding NIHR funded this study.

Disclaimer The funding source had no role in the study design, writing the manuscript, in the decision to submit the manuscript for publication and in data interpretation, collection and analysis.

Competing interests NH is currently undertaking an NIHR clinical fellowship. Provenance and peer review Not commissioned; externally peer reviewed.

Open Access This is an Open Access article distributed in accordance with the terms of the Creative Commons Attribution (CC BY 4.0) license, which permits others to distribute, remix, adapt and build upon this work, for commercial use, provided the original work is properly cited. See: http:// creativecommons.org/licenses/by/4.0/

\section{REFERENCES}

1. Easton JD, Saver JL, Albers GW, et al. Definition and evaluation of transient ischemic attack: a scientific statement for healthcare professionals from the American Heart Association/American Stroke Association Stroke Council; Council on Cardiovascular Surgery and Anesthesia; Council on Cardiovascular Nursing; and thelnterdisciplinary Council on Peripheral Vascular Disease. The American Academy of Neurology affirms the value of this statement as an educational tool for neurologists. Stroke 2009;40:2276-93.

2. Amort M, Fluri F, Weisskopf F, et al. Etiological classifications of transient ischemic attacks: subtype classification by TOAST, CCS and ASCO-a pilot study. Cerebrovasc Dis 2012;33:508-16.

3. Siket MS, Edlow JA. Transient ischemic attack: reviewing the evolution of the definition, diagnosis, risk stratification, and management for the emergency physician. Emerg Med Clin North Am 2012;30:745-70.

4. Epstein SE, Palmeri ST. Mechanisms contributing to precipitation of unstable angina and acute myocardial infarction: implications regarding therapy. Am J Cardiol 1984;54:1245-52.

5. Rothwell PM, Coull AJ, Silver LE, et al. Population-based study of event-rate, incidence, case fatality, and mortality for all acute vascular events in all arterial territories (Oxford Vascular Study). Lancet 2005;366:1773-83.

6. Di Pasquale G, Urbinati S, Perugini E, et al. Interactions between cardiovascular and cerebrovascular disease. Curr Treat Options Neurol 2012;14:557-93. Epub.

7. Adams RJ, Chimowitz MI, Alpert JS, et al; Stroke Council and the Council on Clinical Cardiology of the American Heart Association; American Stroke Association. Coronary risk evaluation in patients with transient ischemic attack and ischemic stroke: a scientific statement for healthcare professionals from the Stroke Council and the Council on Clinical Cardiology of the American Heart Association/American Stroke Association. Circulation 2003;108:1278-90. 
8. Kernan WN, Ovbiagele B, Black HR, et al. Guidelines for the prevention of stroke in patients with stroke and transient ischemic attack: a guideline for healthcare professionals from the American Heart Association/American Stroke Association. Stroke 2014;45:2160-236.

9. MacKay-Lyons M, Gubitz G, Giacomantonio N, et al. Program of rehabilitative exercise and education to avert vascular events after non-disabling stroke or transient ischemic attack (PREVENT Trial): a multi-centred, randomised controlled trial. BMC Neurol 2010; 10:122.

10. Wu CM, Manns BJ, Hill MD, et al. Rapid evaluation after high-risk TIA is associated with lower stroke risk. Can J Neurol Sci 2009;36:450-5.

11. Rothwell PM, Giles MF, Chandratheva A, et al. Effect of urgent treatment of transient ischaemic attack and minor stroke on early recurrent stroke (EXPRESS study): a prospective population-based sequential comparison. Lancet 2007;370:1432-42.

12. National Institute for Health and Care Excellence (NICE). Stroke: diagnosis and initial management of acute stroke and transient ischaemic attack (TIA). London: Royal College of Physicians, 2008.

13. National Institute for Health and Care Excellence (NICE). Lipid modification: cardiovascular risk assessment and the modification of blood lipids for the primary and secondary prevention of cardiovascular disease (NICE guidelines CG181). London: Royal College of Physicians, 2014:1.

14. National Institute for Health and Care Excellence (NICE). Hypertension: clinical management of primary hypertension in adults (NICE hypertension guidelines CG127). London: Royal College of Physicians, 2011:1.

15. Hughes J, Kee F, O'Flaherty M, et al. Modelling coronary heart disease mortality in Northern Ireland between 1987 and 2007: broader lessons for prevention. Eur J Prev Cardio/ 2013;20:310-21.

16. Mackay-Lyons M, Thornton M, Ruggles T, et al. Nonpharmacological interventions for preventing secondary vascular events after stroke or transient ischemic attack. Cochrane Database Syst Rev 2013;(3):CD008656.

17. WHO. Global recommendations on physical activity for health 2010 . http://www.who.int/dietphysicalactivity/factsheet_recommendations/ en/index.html (accessed 29 Nov 2010)

18. Department of Health (b). UK physical activity guidelines, 2011. https://www.gov.uk/government/publications/uk-physical-activityguidelines

19. Blair SN, Kampert JB, Kohl HW, et al. Influences of cardiorespiratory fitness and other precursors on cardiovascular disease and all-cause mortality in men and women. JAMA 1996;276:205-10.

20. Sandvik L, Erikssen J, Thaulow E, et al. Physical fitness as a predictor of mortality among healthy, middle-aged Norwegian men. N Engl J Med 1993;328:533-7.

21. Ekelund LG, Haskell WL, Johnson JL, et al. Physical fitness as a predictor of cardiovascular mortality in asymptomatic North American men. N Engl J Med 1988;319:1379-84.

22. Laukkanen JA, Kurl S, Salonen JT. Cardiorespiratory fitness and physical activity as risk predictors of future atherosclerotic cardiovascular diseases. Curr Atheroscler Rep 2002;4:468-76.

23. Lakka TA, Laukkanen JA, Rauramaa R, et al. Cardiorespiratory fitness and the progression of carotid atherosclerosis in middle-aged men. Ann Intern Med 2001;134:12-20.

24. Lee CD, Folsom AR, Blair SN. Physical activity and stroke risk: a meta-analysis. Stroke 2003;34:2475-81.

25. Myers J, Prakash M, Froelicher V, et al. Exercise capacity and mortality among men referred for exercise testing. N Engl J Med 2002;346:793-801.

26. Seals DR, Hagberg JM, Hurley BF, et al. Endurance training in older men and women. I. Cardiovascular responses to exercise. J Appl Physiol Respir Environ Exerc Physiol 1984;57:1024-9.

27. Duncan $\mathrm{P}$, Richards $\mathrm{L}$, Wallace $\mathrm{D}$, et al. A randomized, controlled pilot study of a home-based exercise program for individuals with mild and moderate stroke. Stroke 1998;29:2055-60.

28. Doll R, Peto R, Boreham J, et al. Mortality in relation to smoking: 50 years' observations on male British doctors. BMJ 2004;328:1519.

29. O'Donnell MJ, Xavier D, Liu L, et al. Risk factors for ischaemic and intracerebral haemorrhagic stroke in 22 countries (the
INTERSTROKE study): a case-control study. Lancet 2010;376: $112-23$

30. Pirie K, Peto R, Reeves GK, et al. The 21st century hazards of smoking and benefits of stopping: a prospective study of one million women in the UK. Lancet 2013;381:133-41.

31. National Institute for Health and Care Excellence (NICE). Smoking cessation: supporting people to stop smoking NICE quality standard [QS43]. August 2013. https://www.nice.org.uk/guidance/qs43 (accessed 23 Jun 2015)

32. Chen GC, Lv DB, Pang Z, et al. Dietary fiber intake and stroke risk: a meta-analysis of prospective cohort studies. Eur J Clin Nutr 2013;67:96-100.

33. Chowdhury R, Stevens S, Gorman D, et al. Association between fish consumption, long chain omega 3 fatty acids, and risk of cerebrovascular disease: systematic review and meta-analysis. BMJ 2012;345:e6698.

34. Rees K, Hartley L, Flowers N, et al. 'Mediterranean' dietary pattern for the primary prevention of cardiovascular disease. Cochrane Database Syst Rev 2013;(8):CD009825.

35. Gorelick PB. Stroke prevention therapy beyond antithrombotics: unifying mechanisms in ischemic stroke pathogenesis and implications for therapy: an invited review. Stroke 2002;33:862-75.

36. Iso $\mathrm{H}$, Jacobs DR, Wentworth $\mathrm{D}$, et al. Serum cholesterol levels and six-year mortality from stroke in 350,977 men screened for the multiple risk factor intervention trial. N Engl J Med 1989;320:904-10.

37. O'Donnell MJ, Xavier D, Liu L, et al. Risk factors for ischaemic and intracerebral haemorrhagic stroke in 22 countries (the INTERSTROKE study): a case-control study. Lancet 2010;376: $112-23$.

38. Everson-Rose SA, Roetker NS, Lutsey PL, et al. Chronic stress, depressive symptoms, anger, hostility, and risk of stroke and transient ischemic attack in the multi-ethnic study of atherosclerosis. Stroke 2014;45:2318-23.

39. Moran GM, Fletcher B, Feltham MG, et al. Fatigue, psychological and cognitive impairment following transient ischaemic attack and minor stroke: a systematic review. Eur J Neurol 2014;21:1258-67.

40. Gill JS, Shipley MJ, Tsementzis SA, et al. Alcohol consumption-a risk factor for hemorrhagic and non-hemorrhagic stroke. Am J Med 1991;90:489-97.

41. Department of Health, Social Services and Public Safety Northern Ireland. New strategic direction for alcohol and drugs - phase 2, 2011 - 2016: a framework for reducing alcohol and drug related harm in Northern Ireland. UK: Department of Health, Social Services and Public Safety Northern Ireland, 2011.

42. World Health Organization (WHO). World report on disability. Geneva: WHO, 2011.

43. World Health Organization (WHO). Global action plan for the prevention and control of non-communicable diseases. Geneva: WHO, 2013.

44. Lawler PR, Filion KB, Eisenberg MJ. Efficacy of exercise-based cardiac rehabilitation post-myocardial infarction: a systematic review and meta-analysis of randomized controlled trials. Am Heart $J$ 2011;162:571-84.

45. Heran BS, Chen JM, Ebrahim S, et al. Exercise-based cardiac rehabilitation for coronary heart disease. Cochrane Database Syst Rev 2011;(1):CD001800.

46. Dalal HM, Zawada A, Jolly K, et al. Home based versus centre based cardiac rehabilitation: Cochrane systematic review and metaanalysis. BMJ 2010;340:b5631.

47. Clark AM, Haykowsky M, Kryworuchko J, et al. A meta-analysis of randomized control trials of home-based secondary prevention programs for coronary artery disease. Eur J Cardiovasc Prev Rehabil 2010;17:261-70.

48. Smith KM, Arthur HM, McKelvie RS, et al. Differences in sustainability of exercise and health-related quality of life outcomes following home or hospital-based cardiac rehabilitation. Eur $J$ Cardiovasc Prev Rehabil 2004:11:313-9.

49. Alnozha M, Broustet J, Falasea A, et al. Rehabilitation after cardiovascular diseases, with special emphasis on developing countries. Report of a WHO Expert Committee. World Health Organ Tech Rep Ser 1993;831:1-122.

50. National Institute for Health and Care Excellence. Clinical guideline [CG48]: MI - secondary prevention 2010. 